\title{
Características de carcaça determinadas por ultrassonografia em tempo real e pós-abate de cordeiros terminados em confinamento com diferentes níveis de energia na dieta ${ }^{1}$
}

\section{Felipe Queiroga Cartaxo², Wandrick Hauss de Sousa ${ }^{3}$, Marcílio Fontes Cezar ${ }^{4}$, Roberto Germano Costa $^{5}$, Maria das Graças Gomes Cunha ${ }^{3}$, Severino Gonzaga Neto ${ }^{6}$}

\footnotetext{
1 Projeto financiado pelo convênio FINEP/EMEPA-PB.

2 Programa de Doutorado Integrado em Zootecnia/UFPB.

${ }^{3}$ EMEPA - PB.

${ }^{4}$ Departamento de Medicina Veterinária/CSTR/UFCG - Patos-PB.

${ }^{5}$ Departamento de Agropecuária/CFT/UFPB-Bananeiras-PB.

${ }^{6}$ Departamento de Zootecnia/CCA/UFPB - Areia-PB.
}

RESUMO - Objetivou-se avaliar as características de carcaça por ultrassonografia em tempo real e após o abate e a relação entre essas características e os rendimentos de carcaça de cordeiros de diferentes genótipos terminados em confinamento com diversos níveis de energia na dieta. Foram utilizados 54 cordeiros não-castrados — 18 Santa Inês puros (SI),

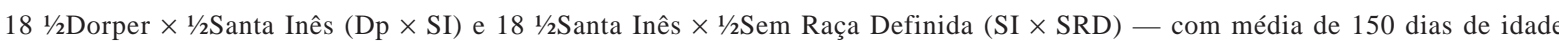
e peso médio de 22,60 kg no início do experimento. As dietas continham 17\% de proteína bruta e 2,40 Mcal $/ \mathrm{kg}$ MS e 2,90 Mcal/kg MS. As mensurações realizadas por ultrassonografia e diretamente na carcaça dos cordeiros apresentaram resultados similares. Os cordeiros alimentados com a dieta contendo 2,90 Mcal $/ \mathrm{kg}$ apresentaram maior área de olho-de-lombo, melhor conformação e acabamento de carcaça e maior quantidade de gordura pélvico-renal. Os cordeiros Dp $\times$ SI apresentaram maior área de olho-de-lombo e musculosidade por $100 \mathrm{~kg}$ de PV em comparação aos SI $\times$ SRD e foram superiores a todos os genótipos quanto à espessura de gordura subcutânea, à conformação e ao acabamento de carcaça. O marmoreio observado nos cordeiros Dp $\times$ SI foi superior aos dos Santa Inês. As correlações das medidas tomadas por ultrassonografia e na carcaça foram altas e significativas, exceto o marmoreio. Houve correlação significativa entre conformação da carcaça e acabamento, marmoreio, espessura de gordura subcutânea e gordura pélvico-renal. As gorduras de cobertura avaliadas subjetivamente e objetivamente apresentaram correlações altas e significativas. A dieta e o genótipo influenciam as características de carcaça de cordeiros.

Palavras-chave: acabamento, área de olho-de-lombo, espessura de gordura, Dorper, marmoreio, Santa Inês

\section{Carcass traits determined by ultrasonography in real time and after slaughter of lambs finished in fedlot with diferent levels of energy in the diet}

\footnotetext{
ABSTRACT - The objective of this study was to evaluate carcass traits through ultrasonography in real time and after slaughter and the relationship between these traits and carcass yields of lambs with different genotypes finished in feedlot with several levels of energy in the diet. It was used 54 non-castrated lambs: 18 pure Santa Inês (SI), $18 \frac{1}{1} 2$ Dorper $\times 1 \frac{1}{2}$ Santa Inês $(\mathrm{Dp} \times \mathrm{SI})$ and 18 1/2Santa Inês $\times 1 / 2$ Without Standard Defined Breed (SI $\times$ WSDB), at an average age of 150 days and at an average body weight of $22.6 \mathrm{~kg}$ at the beginning of the experiment. Diets contained $17 \%$ of crude protein, $2.40 \mathrm{Mcal} / \mathrm{kg}$ $\mathrm{DM}$ and $2.90 \mathrm{Mcal} / \mathrm{kg}$ DM. Measurements made by ultrasonography and directly on carcass of the lambs showed similar results. Lambs fed diets containing $2.90 \mathrm{Mcal} / \mathrm{kg}$ showed larger loin eye area, better carcass conformation and finishing and higher amount of pelvic-renal fat. Lambs Dp $\times$ SI showed larger loin eye areas and muscularity per $100 \mathrm{~kg}$ of body weight in comparison to SI $\times$ SRD lambs and they were superior to all genotypes regarded to subcutaneous fat thickness, conformation and finishing carcass. Marbling observed in Dp $\times$ SI lambs were superior than in Santa Inês lambs. Correlations of measures taken by ultrasonography and on the carcass were high and significant, except marbling. There was a significant correlation among carcass conformation and finishing, marbling, subcutaneous fat thickness and pelvic-renal thickness. Backfat subjectively and objectively evaluated showed high and significant correlations. Diet and genotype influence characteristics of carcass of lambs.
}

Key Words: Dorper, fat thickness, finishing, loin eye area, marbling, Santa Inês 


\section{Introdução}

A pecuária de corte mundial tem procurado melhorar os índices zootécnicos visando maior rentabilidade, seja por meio da melhoria genética dos rebanhos seja pelo uso de pastagens melhoradas, pela formulação de dietas adequadas e pela utilização de novas tecnologias, como a avaliação da carcaça em tempo real por ultrassonografia (Cartaxo \& Sousa, 2008).

A área de olho-de-lombo, a espessura de gordura subcutânea e o marmoreio são características mensuradas por ultrassonografia que estão relacionadas ao ganho de peso diário, rendimento de carcaça, precocidade de acabamento, sabor e suculência da carne. Siqueira \& Fernandes (2000) afirmaram que o estudo dos aspectos qualitativos das carcaças ovinas tem grande importância, haja vista as peculiaridades dos sistemas de produção e dos genótipos utilizados.

A energia contida nas dietas em ovinos pode interferir diretamente nas características de carcaça, uma vez que alta concentração energética tem favorecido o aumento dos depósitos de tecido adiposo. Entretanto, para cordeiros deslanados, cujo acúmulo de tecido adiposo ocorre em grande parte internamente, não se pode afirmar que dietas ricas em energia proporcionarão melhor acabamento e distribuição de tecido adiposo na carcaça.

Nesse sentido é necessária avaliação das características de carcaça entre genótipos, principalmente nas raças e nos cruzamentos mais utilizados na Região Nordeste do Brasil. No entanto, pouco se conhece das características de carcaça do cruzamento do genótipo adaptado às condições ambientais, o SRD, com a Santa Inês. Segundo Sousa et al. (2003), a raça Santa Inês é encontrada em todas as regiões do Brasil, apresentando-se como boa opção para a utilização em sistemas de cruzamentos. Dessa forma, o cruzamento de fêmeas da raça Santa Inês com reprodutores de uma raça especializada para corte, como a Dorper, tem sido adotado para melhoria das características de carcaça.

O objetivo neste estudo foi avaliar as características de carcaça por ultrassonografia em tempo real e pós abate, bem como a relação entre estas com algumas características quantitativas de carcaça de cordeiros Santa Inês puros, $1 \frac{1}{2}$ Dorper $\times 1 / 2$ Santa Inês e $1 \frac{1}{2}$ Santa Inês $\times 1 \frac{1}{2}$ Sem Raça Definida terminados em confinamento submetido a dietas contendo diferentes níveis de energia.

\section{Material e Métodos}

O experimento foi conduzido na Estação Experimental Pendência, pertencente à Empresa Estadual de Pesquisa
Agropecuária da Paraíba (EMEPA-PB), localizada no município de Soledade - PB, situada nas coordenadas geográficas com latitude de $7^{\circ} 8^{\prime} 18^{\prime \prime}$ S e $36^{\circ} 27^{\prime}$ 2" W, com altitude de $534 \mathrm{~m}$ e temperatura média de $30^{\circ} \mathrm{C}$.

Foram utilizados 54 cordeiros não-castrados, sendo 18 da raça Santa Inês puros (SI), 18 1/2 Dorper $\times 1 \frac{1}{2}$ Santa Inês (Dp $\times$ SI) e $181 \frac{1}{2}$ Santa Inês $\times 1 \frac{1}{2}$ Sem Raça Definida (SI $\times$ SRD), com idade média de 150 dias e peso médio de 22,60 kg no início do experimento.

Os animais foram inicialmente vacinados contra clostridioses e vermifugados com aplicação subcutânea de ivermectina 1\%. Em seguida foram distribuídos em baias individuais medindo $0,80 \times 1,20 \mathrm{~m}$ com acesso livre aos comedouros e bebedouros, onde receberam as dietas (Tabela 1). O período de adaptação foi de 14 dias e as pesagens dos cordeiros foram realizadas a cada 14 dias.

Foi estabelecido como critério de abate o peso vivo de $36,0 \mathrm{~kg}$ (estabelecido em função da demanda dos principais restaurantes e frigoríficos), no entanto, ao final de 63 dias, período máximo de confinamento, todos os cordeiros foram abatidos, independentemente do peso.

A avaliação do escore corporal foi feita por dois examinadores segundo a metodologia descrita por Cezar \& Sousa (2006). Para a atribuição dos escores foram feitas avaliações antes do abate, por meio de exame visual e palpação da região lombar e na inserção da cauda dos cordeiros, com pontuação de 1 a 5 , com intervalos de 0,5.

O ganho de peso médio diário foi obtido pela relação entre o ganho de peso no período de confinamento e o número de dias que cordeiros necessitaram para atingirem o peso de abate ou o período máximo pré-estabelecido para a terminação.

Para avaliação das características de carcaça por ultrassonografia em tempo real, utilizou-se um equipamento de ultrassom, marca ALOKA 500, com sonda acústica de $12 \mathrm{~cm}$ e frequência de 3,5 Mhz e acoplador de silicone, permitindo perfeito acoplamento do transdutor com o corpo do animal. Antes da captação das imagens procedeu-se a tricotomia da região entre a $12^{\underline{a}}$ e $13^{\underline{a}}$ vértebra torácica do lado esquerdo do animal.

A sonda equipada com guia acústica ficou disposta de maneira perpendicular ao comprimento do músculo longissimus dorsi, entre a $12 \underline{\text { a }}$ e $13^{\underline{a}}$ vértebra torácica para mensuração da área de olho-de-lombo (AOLU) e a espessura de gordura subcutânea (EGSU), obtida a 3/4 de distância a partir do lado medial do músculo longissimus dorsi para a lateral da linha dorsolombar, e paralelamente, para obtenção do marmoreio do músculo longissimus dorsi (escala de 0 a 10) por meio de software de avaliação de carcaça BIA PRO PLUS, da empresa Designer Genes Technologies. 
Tabela 1 - Composição alimentar e química das dietas experimentais

\begin{tabular}{lcc}
\hline Composição alimentar & & Nível de energia \\
\cline { 2 - 3 } & 2,40 Mcal EM/kg MS & 2,90 Mcal EM/kg MS \\
\hline Feno de capim-tifton (\%) & 50,00 & 21,20 \\
Milho moído (\%) & 12,80 & 54,30 \\
Farelo de soja (\%) & 16,80 & 20,80 \\
Farelo de trigo (\%) & 19,00 & - \\
Óleo de soja (\%) & - & 2,00 \\
Sal mineral (\%) & 0,50 & 0,50 \\
Calcário calcítico (\%) & 0,90 & 1,20 \\
Composição química & & 17,00 \\
Proteína bruta (\%) & 17,00 & 2,90 \\
Energia metabolizável (Mcal/kg MS) & 2,40 & 27,32 \\
Fibra em detergente neutro (\%) & 52,05 & 80,06 \\
Nutrientes digestíveis totais (\%) & 66,22 & 4,89 \\
Extrato etéreo (\%) & 2,29 & 48,26 \\
Carboidratos não-fibrosos (\%) & 24,74 & 7,08 \\
Matéria mineral (\%) & 5,28 & \\
\hline
\end{tabular}

${ }^{1}$ Composição do sal mineral (por quilograma): Na - 147 g; Ca - 120 g; P - 87 g; S - 18 g; Zn - 3.800 mg; Fe - 3.500 mg; Mn - 1.300 mg; F - 870 mg; Cu - 590 mg; Mo - 300 mg; I - 80 mg; Co - 40 mg; Cr - 20 mg; Se - 15 mg; vit. A (UI) - 250 mg; vit. D (UI) - 100 mg; vit. E (UI) - 500 mg.

Calculou-se a musculosidade dos cordeiros por ultrassonografia in vivo e na carcaça pós-abate pela relação entre as respectivas áreas de olho-de-lombo e o peso de carcaça fria. Também foi determinada musculosidade em relação a $100 \mathrm{~kg}$ de peso vivo, por ultrassonografia in vivo e na carcaça pós-abate.

O abate foi realizado após prévio jejum de sólidos (18 horas) e líquido (12 horas), com posterior suspensão pelas patas traseiras e insensibilização por concussão cerebral seguida da secção de veias jugulares e artérias carótidas para sangria.

Após a sangria e esfola foram retirados o conteúdo gastrintestinal, pele, vísceras, cabeça, patas e órgãos genitais e, em seguida as carcaças foram transportadas para uma câmara frigorífica a $4^{\circ} \mathrm{C}$, onde permaneceram por 24 horas.

Após o período de resfriamento, foram determinadas as características qualitativas das carcaças em ambiente refrigerado, por meio de avaliações da conformação e acabamento da carcaça e quantidade de gordura pélvicorenal. A avaliação da conformação da carcaça foi realizada com ênfase nas regiões anatômicas (perna, garupa, lombo, paleta e seus planos musculares) e o acabamento da carcaça com ênfase na espessura e distribuição dos planos adiposos em relação ao esqueleto de acordo com as categorias e escores demonstrados por Cezar \& Sousa (2007). Ainda com a carcaça suspensa foi feita a determinação da quantidade da gordura pélvico-renal de acordo com metodologia descrita por Cezar \& Sousa (2007).

Realizou-se um corte transversal entre $12^{\mathrm{a}}$ e $13^{\mathrm{a}}$ costelas e na meia-carcaça esquerda, expondo a secção transversal do músculo longissimus dorsi, foi realizada a avaliação da marmorização, textura e coloração da carne, conforme
Cezar \& Sousa (2007). Ainda no mesmo músculo, com o uso de película plástica transparente, foi determinada a área de olho-de-lombo na carcaça (AOLC), por meio da obtenção com régua da largura máxima (A) e a profundidade máxima (B) para determinação de área de acordo com a fórmula: $\mathrm{AOL}=(\mathrm{A} / 2 * \mathrm{~B} / 2) \pi$.

A espessura de gordura subcutânea na carcaça (EGSC) foi medida em paquímetro digital, da mesma forma como foi medida por ultrassom. A espessura máxima de gordura de cobertura sobre a superfície da $13^{\underline{a}}$ costela, a $11 \mathrm{~cm}$ da linha dorso-lombar (medida GR) foi determinada pela profundidade da gordura sobre a $12^{\underline{a}}$ costela a $11 \mathrm{~cm}$ de distância da linha média lombo, utilizando-se paquímetro digital.

Os dados das variáveis estudadas foram submetidos a uma análise de variância, obedecendo a um delineamento inteiramente casualizado em um esquema fatorial $3 \times 2$ (três genótipos e duas dietas) utilizando-se o teste $\mathrm{F}$ para comparação dos quadrados médios dos fatores testados.

O modelo estatístico utilizado foi o seguinte: $Y_{i j}=\mu+G_{i}$ $+D_{i}+G_{i j}+\varepsilon_{i j}$, em que $Y_{i j}=$ valor observado da variável dependente estudada, $\mu=$ média geral; $G_{i}=$ efeito do genótipo $\mathrm{i} ; \mathrm{D}_{\mathrm{i}}=$ efeito da dieta $\mathrm{j} ; \mathrm{GD}_{\mathrm{ij}}=$ interação do genótipo e dieta e $\varepsilon_{\mathrm{ij}}=$ erro aleatório associado a cada observação e as médias foram comparadas pelo teste Tukey a 5\% de probabilidade. Utilizou-se o procedimento PROC CORR do programa SAS (2001).

\section{Resultados e Discussão}

Não foi observado efeito significativo da interação dieta e genótipo, portanto, as variáveis estão apresentadas de forma independente (Tabela 2). O peso vivo final foi 
Tabela 2 - Pesos e características de carcaça por ultrassonografia em tempo real e pós-abate de cordeiros

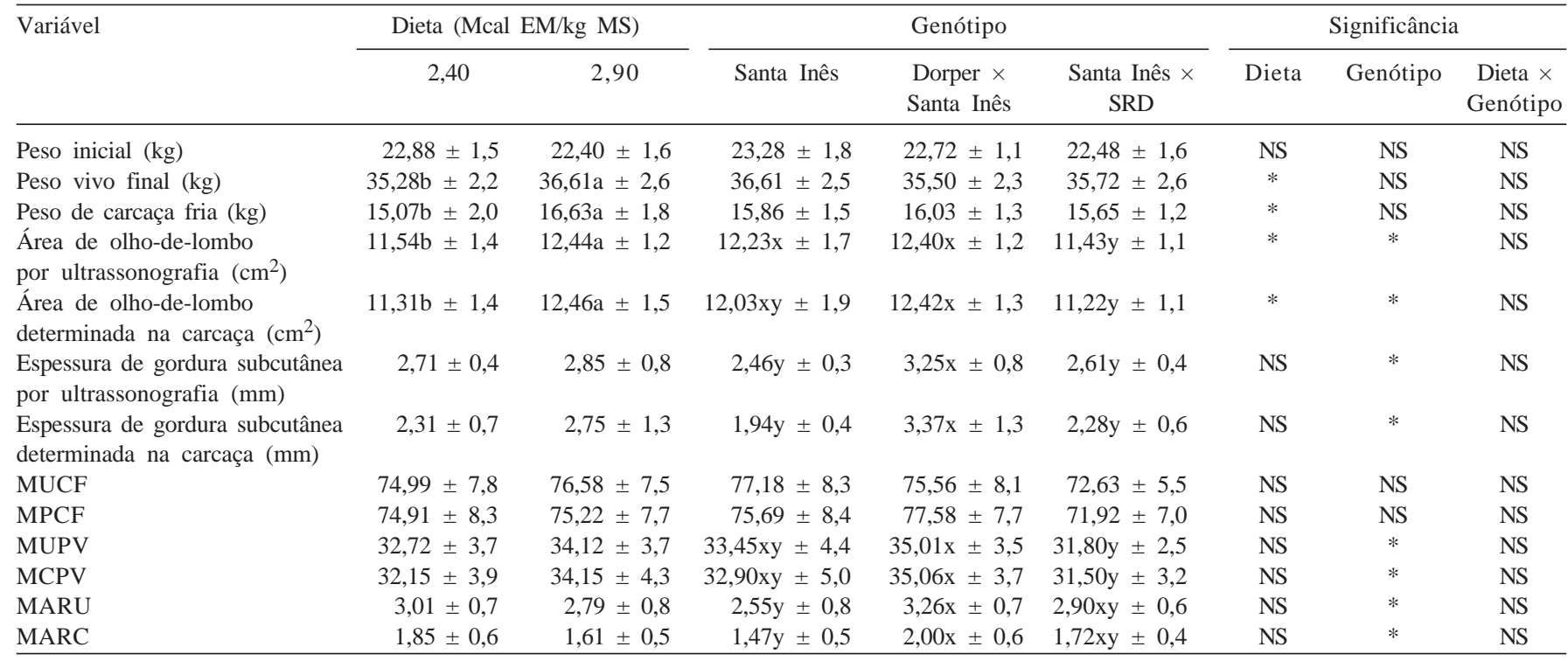

MUCF = musculosidade por ultrassonografia em relação ao peso da carcaça fria; MUPV = musculosidade por ultrassonografia em relação ao peso vivo final; MPCF = musculosidade na carcaça em relação ao peso da carcaça fria; MCPV = musculosidade na carcaça em relação a $100 \mathrm{~kg}$ de peso vivo; MARU = marmoreio por ultrassonografia; MARC = marmoreio na carcaça em função da dieta e do genótipo.

a,b Médias seguidas por letras distintas diferem entre si pelo teste Tukey $(\mathrm{P}<0,05)$ em função da dieta.

x,y,z Médias seguidas por letras distintas diferem entre si pelo teste Tukey $(P<0,05)$ em função do genótipo.

NS: valores não-significativos; * $(\mathrm{P}<0,05) ; * *(\mathrm{P}<0,01)$.

maior $(\mathrm{P}<0,05)$ para os cordeiros alimentados com a dieta contendo 2,90 Mcal/kg MS, e não houve efeito significativo ( $\mathrm{P}>0,05)$ dos genótipos. O maior aporte de energia da referida dieta favoreceu o maior acúmulo de tecidos e refletiu em maior peso vivo final e de carcaça fria.

A dieta e o genótipo influenciaram $(\mathrm{P}<0,05)$ a área de olho-de-lombo, obtida por ultrassonografia in vivo e na carcaça pós-abate. Houve comportamento semelhante com relação às áreas de olho-de-lombo realizadas por ultrassonografia in vivo e na carcaça pós-abate, indicando que o aumento na concentração de energia resultou em maior área de olho-de-lombo, decorrente do maior do peso de carcaça fria obtido pelos cordeiros alimentados com a dieta contendo alta concentração de energia.

Na avaliação realizada por ultrassonografia in vivo, ovinos Dorper $\times$ Santa Inês e Santa Inês apresentaram área de olho-de-lombo superior $(\mathrm{P}<0,05)$ à dos Santa Inês $\times \mathrm{SRD}$. Na mensuração realizada na carcaça pós-abate, os cordeiros $\mathrm{Dp} \times$ SI apresentaram maior $(\mathrm{P}<0,05)$ área de olho-de-lombo em comparação aos Santa Inês $\times$ SRD e Santa Inês.

Não houve efeito $(\mathrm{P}>0,05)$ da dieta sobre a espessura de gordura subcutânea avaliada por ultrassonografia in vivo e na carcaça pós-abate. Contudo, esperava-se que a dieta com elevado nível de energia propiciasse uma maior cobertura de gordura na carcaça dos cordeiros, uma vez que, Berchielli et al. (2006) afirmaram que a energia da dieta é rapidamente depositada e Clementino et al. (2007) citaram que a maior quantidade de ácido propiônico em dietas com maior percentual de concentrado, contribuiu para o aumento da energia disponível, com favorecimento de maior porcentagem de gordura subcutânea e intermuscular.

Com relação aos genótipos avaliados a espessura de gordura subcutânea por ultrassonografia in vivo e na carcaça pós-abate foi observado efeito significativo $(\mathrm{P}<0,05)$. Os cordeiros Dorper $\times$ Santa Inês foram superiores $(\mathrm{P}<0,05)$ aos Santa Inês e aos Santa Inês $\times \mathrm{SRD}$, o que possivelmente está relacionado ao genótipo, sendo que a presença da raça Dorper tenha propiciado o aumento da proteção de carcaça durante o resfriamento. Diferenças entre genótipos também foram observadas por Landim et al. (2007), que estudaram a espessura de gordura subcutânea por ultrassonografia in vivo em cordeiros e verificaram que os mestiços Texel $\times$ Santa Inês foram superiores aos Santa Inês e aos Bergamácia $\times$ Santa Inês.

A musculosidade dos cordeiros tomando como base AOLU e AOLC e o peso de carcaça fria não foi influenciada $(\mathrm{P}>0,05)$ pela dieta e genótipo. No entanto, houve efeito $(\mathrm{P}<0,05)$ de genótipo sobre a musculosidade em relação a 100 kg de peso vivo, a qual parece melhor representar a musculosidade da carcaça, provavelmente devido ao ajuste por peso, o qual reduziu o efeito do ambiente, propiciando maior eficácia. Segundo Prado et al. (2004) a área de olho-delombo é uma medida usada como indicativo de desenvolvimento muscular, por sua vez, Cartaxo \& Sousa (2008) afirmaram que a área de olho-de-lombo é um dos indicativos da proporção de músculo na carcaça. 
A marmorização não foi influenciada $(\mathrm{P}>0,05)$ pela dieta por ultrassonografia in vivo e na carcaça pós-abate, entretanto, os cordeiros Dorper $\times$ Santa Inês apresentaram maior marmoreio quando comparados aos Santa Inês nas distintas mensurações realizadas. De acordo com os resultados obtidos, a marmorização não é aumentada pelo nível de energia presente na dieta, porém, o genótipo é determinante na melhoria desta característica. Neste sentido, Crews Jr. et al. (2003) encontraram alta estimativa de herdabilidade para a marmorização $(0,54)$ em bovinos, fato que comprova que a ultrassonografia pode auxiliar na identificação de cruzamentos superiores.

Ítavo et al. (2009) avaliando o efeito da dieta (própolis verde, própolis marrom e monensina sódica) sobre a quantidade de marmoreio obtida por ultrassonografia in vivo em cordeiros SRD, também não observaram diferença significativa. Já Suguisawa et al. (2008) encontraram superioridade $(\mathrm{P}<0,05)$ na deposição do marmoreio dos cordeiros Texel $\times$ SRD nas três avaliações realizadas por ultrassonografia em relação aos Santa Inês $\times$ SRD. Platter et al. (2005) ressaltaram a importância da gordura intramuscular em atributos sensoriais da carne, como sabor e suculência.

A área de olho-de-lombo por ultrassonografia in vivo foi altamente $(\mathrm{P}<0,001)$ correlacionada com a mesma medida na carcaça pós-abate, demonstrando ser um método eficaz de predição (Tabela 3), concordando Junkuszew \& Ringdorfer (2005), Cartaxo \& Sousa (2008) e Andrighetto et al. (2009). Coeficiente superior $(0,85)$ ao do presente estudo foi reportado por Ítavo et al. (2009) com cordeiros SRD.

Tabela 3 - Coeficientes de correlação de Pearson entre as mensurações por ultrassonografia em tempo real e na carcaça

\begin{tabular}{lc}
\hline Característica & Coeficiente de correlação (r) \\
\hline AOLU vs AOLC & $0,70^{* * *}$ \\
GPMD vs AOLC & $0,29^{*}$ \\
GPMD vs AOLU & $0,39^{* *}$ \\
GPMD vs ESGC & $-0,02$ \\
GPMD vs ESGU & 0,01 \\
AOLC vs EGSC & 0,23 \\
AOLC vs MPCQ & $0,73^{* * *}$ \\
AOLC vs MCPV & $0,85^{* * *}$ \\
MUCQ vs AOLC & $0,30^{*}$ \\
MUPV vs AOLC & $0,55^{* * *}$ \\
ESGU vs EGSC & $0,73^{* * *}$ \\
MUCQ vs MPCQ & $0,55^{* * *}$ \\
MUPV vs MCPV & $0,68 * * *$ \\
MARU vs MARC & 0,22 \\
MARC vs EGS & 0,18
\end{tabular}

*** $(\mathrm{P}<0,001) * *(\mathrm{P}<0,01) *(\mathrm{P}<0,05)$.

AOLU - área de olho-de-lombo por ultrassonografia; AOLC - área de olho-delombo na carcaça; GPMD - ganho de peso médio diário; MUCF - AOLU/PCF; MPCF - AOLC/PCF; MUPV - AOLU/100 kg PV; MCPV- AOLC/100 kg PV; EGSU- espessura de gordura subcutânea por ultrassonografia; EGSC - espessura de gordura subcutânea na carcaça; MARU - marmoreio por ultrassonografia; MARC - marmoreio na carcaça.
O ganho de peso médio diário foi correlacionado $(\mathrm{P}<0,05)$ com a área de olho-de-lombo na carcaça pós-abate $(\mathrm{P}<0,01)$ e com a área de olho lombo por ultrassonografia in vivo.

A área de olho-de-lombo não foi correlacionada $(\mathrm{P}>0,05)$ com espessura de gordura subcutânea, devido a sequência de desenvolvimento dos tecidos, sendo que o desenvolvimento do tecido muscular e adiposo não é simultâneo, segundo Cartaxo \& Sousa (2008). Resultados semelhantes foram observados por Fernández et al. (1997) e Tarouco et al. (2005). Cartaxo \& Sousa (2007) também verificaram correlação significativa entre área de olho-de-lombo mensurada antes do abate e ganho de peso médio diário, da mesma forma, no presente estudo não foi constatada correlação entre estas medidas com a espessura de gordura subcutânea na carcaça.

A área de olho-de-lombo medida na carcaça apresentou correlação altamente significativa $(\mathrm{P}<0,001)$ com as duas musculosidades estudadas (MPCF e MCPV), o que corrobora os relatos dos pesquisadores (Prado et al., 2004; Cartaxo \& Sousa, 2008) de que essa área representa a musculosidade da carcaça nos animais. A correlação da área de olho-delombo na carcaça com a musculosidade ajustada para $100 \mathrm{~kg}$ de peso vivo, além de ter apresentado maior coeficiente $(0,85)$ em comparação à musculosidade com base no peso de carcaça fria $(0,73)$, também conseguiu identificar as mesmas diferenças encontradas para áreas de olho-delombo por ultrassonografia e na carcaça (Tabela 2). Isso evidencia que a MUPV foi mais acurada para distinguir a musculosidade da carcaça de cordeiros, pois foi mais precisa na diferenciação entre genótipos, se assemelhando às mensurações das áreas de olho-de-lombo.

Correlação alta e significativa ( $\mathrm{P}<0,001)$ foi observada entre espessura de gordura por ultrassonografia in vivo e na carcaça pós-abate. Como a maioria das pesquisas realizadas em pequenos ruminantes é com animais muito jovens, resultado como esse não é comum, devido a pequena espessura de gordura subcutânea presente na carcaça resultando em dificuldades na interpretação das imagens. Delfa et al. (1991) com ovelhas adultas da raça Aragonesa relataram, alta e significativa correlação $(\mathrm{P}<0,01)$, no entanto, Ítavo et al. (2009) com cordeiros SRD encontraram correlação inferior $(0,39)$ ao obtido no presente estudo.

As musculosidades por ultrassonografia com as mensuradas na carcaça (MUCF vs MPCF e MUPV vs MCPV) foram altamente correlacionadas $(\mathrm{P}<0,001)$, porém, a correlação entre MUPV vs MCPV resultou em coeficiente 0,68 ; maior que 0,55 observado para a correlação entre MUCF vs MPCF, o que sugere a maior adequação da musculosidade ajustada para $100 \mathrm{~kg}$ de peso vivo. 
A correlação entre a marmorização por ultrassonografia in vivo e na carcaça pós-abate não foi significativa $(\mathrm{P}>0,05)$, o que pode ser atribuído a diferença entre escalas de cada escore pós-abate com escala maior $(0,50)$ e in vivo menor $(0,01)$.

A marmorização não se correlacionou $(\mathrm{P}>0,05)$ com a espessura de gordura subcutânea, ambas mensuradas na carcaça. Isto indica que a cobertura de gordura na carcaça não ocorre de forma simultânea com o depósito de gordura intramuscular presente no músculo longissimus dorsi.

Não foi observado efeito significativo da interação dieta × genótipo, portanto, as variáveis estão apresentadas de forma independente (Tabela 4). Os cordeiros alimentados com a dieta contendo 2,90 Mcal/kg MS apresentaram melhor $(\mathrm{P}<0,05)$ conformação e acabamento de carcaça em comparação àqueles que receberam dieta contendo 2,40 Mcal/kg MS, com maior quantidade e melhor distribuição muscular e adiposa.

Os cordeiros Dp $\times$ SI obtiveram conformação e acabamento de carcaça superior $(\mathrm{P}<0,05)$ o que evidência que a raça Dorper no cruzamento com a Santa Inês poderia influenciar positivamente durante o processo de resfriamento. Segundo Sañudo et al. (1997), a utilização de raças para produção de carne influenciam as características da carcaça de cordeiros, principalmente acabamento e qualidade da carne.
Houve efeito da dieta $(\mathrm{P}<0,05)$ sobre deposição da gordura pélvico-renal, com maior escore em carcaças de cordeiros alimentados com 2,90 Mcal/kg MS, o que é característico de ovinos deslanados quando há aumento da energia. Foi observado maior $(\mathrm{P}<0,05)$ escore para deposição de gordura pélvico-renal nas carcaças dos cordeiros Santa Inês $\times$ SRD.

As carcaças dos cordeiros Dorper $\times$ Santa Inês foram superiores $(\mathrm{P}<0,05)$ quanto ao marmoreio aos Santa Inês e Santa Inês $\times$ SRD. Resultados semelhantes foram reportados por Gutiérrez et al. (2005) e por Almeida et al. (2006) com diferenças entre genótipos.

Não houve efeito $\mathrm{P}(>0,05)$ da dieta e de genótipo sobre a textura e coloração do músculo longissimus dorsi. Segundo Cezar \& Sousa (2007), o principal fator que diferencia a textura e a coloração da carne na carcaça é a idade do animal, o que provavelmente foi o fator determinante da similaridade neste ensaio, devido à idade.

A conformação e o acabamento de carcaça tiveram significativa correlação (Tabela 5) com o tecido adiposo subcutâneo presente na carcaça, o que indica que carcaças bem conformadas e acabadas apresentam bom escore corporal, evidenciado pela correlação obtida $(\mathrm{P}<0,001)$. Diante das altas correlações $(\mathrm{P}<0,001)$ entre o acabamento e a cobertura de gordura na medida na carcaça, comprovou-se

Tabela 4 - Características qualitativas de carcaça de cordeiros de diversos genótipos alimentados com rações com dois níveis energético

\begin{tabular}{|c|c|c|c|c|c|c|c|c|}
\hline \multirow[t]{2}{*}{ Variável } & \multicolumn{2}{|c|}{ Dieta (Mcal EM/kg MS) } & \multicolumn{3}{|c|}{ Genótipo } & \multicolumn{3}{|c|}{ Significância } \\
\hline & 2,40 & 2,90 & Santa Inês & $\begin{array}{l}\text { Dorper } \times \\
\text { Santa Inês }\end{array}$ & $\begin{array}{c}\text { Santa Inês } \times \\
\text { SRD }\end{array}$ & Dieta & Genótipo & $\begin{array}{c}\text { Dita } \times \\
\text { Genótipo }\end{array}$ \\
\hline Conformação da carcaça & $2,53 b \pm 0,6$ & $2,90 \mathrm{a} \pm 0,7$ & $2,41 \mathrm{y} \pm 0,5$ & $3,27 x \pm 0,6$ & $2,47 y \pm 0,5$ & $*$ & $*$ & NS \\
\hline Acabamento da carcaça & $2,37 b \pm 0,5$ & $2,96 a \pm 0,6$ & $2,36 y \pm 0,3$ & $3,16 x \pm 0,6$ & $2,47 y \pm 0,5$ & $*$ & * & NS \\
\hline Gordura pélvico-renal & $2,22 b \pm 0,3$ & $2,62 \mathrm{a} \pm 0,4$ & $2,19 \mathrm{y} \pm 0,5$ & $2,47 x y \pm 0,4$ & $2,61 x \pm 0,3$ & $*$ & $*$ & NS \\
\hline Textura & $4,00 \pm 0,0$ & $4,00 \pm 0,0$ & $4,00 \pm 0,0$ & $4,00 \pm 0,0$ & $4,00 \pm 0,0$ & NS & NS & NS \\
\hline Marmoreio & $1,85 \pm 0,6$ & $1,61 \pm 0,5$ & $1,47 y \pm 0,5$ & $2,00 x \pm 0,6$ & $1,72 x y \pm 0,4$ & NS & * & NS \\
\hline Coloração & $3,92 \pm 0,2$ & $3,96 \pm 0,1$ & $3,97 \pm 0,1$ & $3,91 \pm 0,2$ & $3,94 \pm 0,1$ & NS & NS & NS \\
\hline
\end{tabular}

a,b,c Médias seguidas por letras distintas diferem entre si pelo teste Tukey $(\mathrm{P}<0,05)$ em função da dieta.

$\mathrm{x}, \mathrm{y}$ Médias seguidas por letras distintas diferem entre si pelo teste Tukey $(\mathrm{P}<0,05)$ em função do genótipo

NS: valores não-significativos; * $(\mathrm{P}<0,05) ; * *(\mathrm{P}<0,01)$.

Tabela 5 - Coeficientes de correlação de Pearson entre as características qualitativas e quantitativas de carcaça

\begin{tabular}{|c|c|c|c|c|c|c|c|}
\hline Variável & Acabamento & $\begin{array}{c}\text { Gordura } \\
\text { pélvico-renal }\end{array}$ & Marmoreio & $\begin{array}{c}\text { Espessura de } \\
\text { gordura subcutânea }\end{array}$ & $\begin{array}{l}\text { Medida } \\
\text { GR }\end{array}$ & $\begin{array}{c}\text { Área de } \\
\text { olho-de-lombo }\end{array}$ & $\begin{array}{l}\text { Escore } \\
\text { corporal }\end{array}$ \\
\hline Conformação & $0,44 * *$ & 0,21 & $0,29 *$ & $0,42 * *$ & $0,37 * *$ & 0,26 & $0,52 * * *$ \\
\hline Acabamento & & $0,34 * *$ & 0,15 & $0,68 * * *$ & $0,55 * * *$ & $0,38 * *$ & $0,53 * * *$ \\
\hline Marmoreio & & & & 0,18 & 0,26 & 0,15 & 0,23 \\
\hline Espessura de gordura subcutânea & & & & & $0,82 * * *$ & 0,23 & $0,46 * *$ \\
\hline Medida GR & & & & & & 0,23 & $0,43 * *$ \\
\hline
\end{tabular}

**** $(\mathrm{P}<0,001) * *(\mathrm{P}<0,01) *(\mathrm{P}<0,05)$.

Medida GR = espessura máxima de gordura de cobertura sobre a superfície da 13 ạ costela, a $11 \mathrm{~cm}$ da linha dorso-lombar. 
que a avaliação visual realizada por técnicos experientes e treinados pode identificar carcaças com maior proteção ao resfriamento.

A conformação da carcaça apresentou correlação significativa $(\mathrm{P}<0,05)$ com marmoreio, tendência comprovada pelo fato de que os cordeiros com maiores escores para conformação da carcaça também apresentaram os maiores escores para marmoreio. Isso pode ser um indicativo de que as raças especializadas para corte, cuja principal característica é boa conformação, devem conter maior quantidade de gordura intramuscular.

A correlação entre o acabamento de carcaça e a gordura pélvico-renal foi mais significativa $(\mathrm{P}<0,01)$ que entre gordura pélvico-renal e espessura de gordura subcutânea $(\mathrm{P}<0,05)$, o que evidencia que, em cordeiros deslanados, o acúmulo de gordura de cobertura ocorreu simultaneamente à deposição das gorduras pélvica e renal.

Foi observada alta correlação $(\mathrm{P}<0,001)$ entre a espessura de gordura subcutânea e a medida GR e com o maior coeficiente $(0,82)$, indicando que ambas as medidas representam de forma eficaz a cobertura do tecido adiposo na carcaça de cordeiros. Esta correlação é importante, pois a medida GR pode ser utilizada para medir a gordura da carcaça em cordeiros deslanados quando abatidos muito jovens, em que a espessura de gordura subcutânea é pequena e de difícil medição.

A área de olho-de-lombo apresentou correlação significativa $(\mathrm{P}<0,01)$ com o acabamento de carcaça, o que provavelmente esteja ligado ao acúmulo localizado de gordura, repercutindo em melhor acabamento, com aumento simultâneo da área de olho-de-lombo. A correlação entre a área de olho-de-lombo e a espessura de gordura subcutânea não foi significativa $(\mathrm{P}>0,05)$, corroborando os resultados verificados por Fernádez et al.(1997)e Cartaxo \& Sousa (2008).

\section{Conclusões}

Dietas contendo 2,90 Mcal/kg MS são recomendadas por proporcionar maior área de olho-de-lombo, melhor conformação e acabamento de carcaça em comparação a dietas contendo 2,40 Mcal/kg MS. A utilização da raça Dorper em cruzamentos com a Santa Inês melhora a conformação e o acabamento de carcaça. A ultrassonografia é eficaz na avaliação das características área de olho-delombo e espessura de gordura subcutânea, uma vez que as medidas são semelhantes às obtidas diretamente na carcaça.

\section{Referências}

ALMEIDA, H.S.L.; PIRES, C.C.; GALVANI, D.B. et al. Características de carcaça de cordeiros Ideal e cruzas Border Leicester $x$ Ideal submetidos a três sistemas alimentares. Ciência Rural, v.36, n.5, p.1546-1552, 2006.

ANDRIGHETTO, C.; JORGE, A.M.; CERVIERI, R.C. et al. Relação entre medidas ultrassônicas e da carcaça de bubalinos Murrah abatidos em diferentes períodos de confinamento. Revista Brasileira de Zootecnia, v.38, n.9, p.1762-1768, 2009.

BERCHIELLI, T.T.; PIRES, A.V.; OLIVEIRA, S.G. Nutrição de ruminantes. Jaboticabal: Funep, 2006. 583p.

CARR, M.A.; WALDRON, D.F.; WILLINGHAN, T.D. Relationships among weights, ultrasound and carcass characteristics in Boer-cross goats. Sheep and goat, wool and Mohair CPR. College Station: Texas Agricultural Experimental Station Research Reports, 2002. p.55-59.

CARTAXO, F.Q.; SOUSA, W.H. Relação entre medidas da área de olho-de-lombo por ultrassonografia e na carcaça de cordeiros em diferentes períodos em confinamento. In: SIMPÓSIO INTERNACIONAL SOBRE CAPRINOS E OVINOS DE CORTE, 3., 2007, João Pessoa. Anais... João Pessoa: 2007. (CD-ROM).

CARTAXO, F.Q.; SOUSA, W.H. Correlações entre as características obtidas in vivo por ultra-som e as obtidas na carcaça de cordeiros terminados em confinamento. Revista Brasileira de Zootecnia, v.37, n.8, p.1490-1495, 2008.

CEZAR, M.F.; SOUSA, W.H. Avaliação e utilização da condição corporal como ferramenta de melhoria da reprodução e produção de ovinos e caprinos de corte. Revista Brasileira de Zootecnia, v.35, p.541-565, 2006 (supl. especial).

CEZAR, M.F.; SOUSA, W.H. Carcaças ovinas e caprinas: obtenção-avaliação-classificação. Uberaba: Editora Agropecuária Tropical, 2007. 232p.

CLEMENTINO, R.H.; SOUSA, W.H.; MEDEIROS, A.N. et al. Influência dos níveis de concentrado sobre os cortes comerciais, os constituintes não-carcaça e os componentes da perna de cordeiros confinados. Revista Brasileira de Zootecnia, v.36, n.3, p.681-688, 2007.

CREWS JR., D.H.; POLLAK, E.J.; WEABER, R.L. et al. Genetic parameters for carcass traits and their live animal indicators in Simmental cattle. Journal of Animal Science, v.81, p.1427-1433, 2003.

DELFA, R.; TEIXEIRA, A.; BLASCO, I. et al. Ultrasonic estimates of fat thickness, $\mathrm{C}$ measurement and longissimus dorsi depth in Rasa Aragonesa ewes with same body condicion score. Options Méditerranéennes - Série Séminaires, n.13, p.19-24, 1991.

FERNÁNDEZ, C.; GALLEGO, L.; QUINTANILLA, A. Lamb fat thickness and longissimus muscle area measured by a computerized ultrasonic system. Small Ruminant Research, v.26, p.277-282, 1997

GUTIÉRREZ, J.; RUBIO, M.S.; MÉNDEZ, R.D. Effects of crossbreeding Mexican Pelibuey sheep with Rambouillet and Suffolk on carcass traits. Meat Science, v.70, p.1-5, 2005.

ÍTAVO, C.C.B.F.; MORAIS, M.G.; COSTA, C. et al. Características de carcaça, componentes corporais e rendimento de cortes de cordeiros confinados recebendo dieta com própolis ou monensina sódica. Revista Brasileira de Zootecnia, v.38, n.5, p.898-905, 2009.

JUNKUSZEW, A.; RINGDORFER, F. Computer tomography and ultrasound measurement at methods for the body composition of lambs. Small Ruminant Research, v.56, p.121-125, 2005.

LANDIM, A.V.; PASCOA, L.; McMANUS, C. et al. Utilização da ultrassonografia em cordeiros provenientes das raças Santa Inês, Bergamácia, Texel e seus cruzamentos. In: REUNIÃO ANUAL DA SOCIEDADE BRASILEIRA DE ZOOTECNIA, 44., 2007, 
Jaboticabal. Anais... Jaboticabal: Sociedade Brasileira de Zootecnia, 2007. (CD-ROM).

PLATTER, W.J.; TATUM, J.D.; BELK, K.E. et al. Effects of marbling and shear force on consumers' willingness to pay for beef strip loin steaks. Journal of Animal Science, v.83, p.890-899, 2005.

PRADO, C.S.; PÁDUA, J.T.; CORREA, M.P.C. et al. Comparação de diferentes métodos de avaliação da área de olho-de-lombo e cobertura de gordura em bovinos de corte. Ciência Animal Brasileira, v.5, n.3, p.141-149, 2004

SAÑUDO, C.; CAMPO, M.M.; SIERRA, I. et al. Breed effect on carcass and meat quality of suckling lambs. Meat Science, v.46, n.4, p.357-365, 1997.

SIQUEIRA, E.R.; FERNANDES, S. Efeito do genótipo sobre as medidas objetivas e subjetivas da carcaça de cordeiros terminados em confinamento. Revista Brasileira de Zootecnia, v.29, n.1, p.306-311, 2000.
SOUSA W.H.; LÔBO, R.N.B.; MORAIS, O.R. Ovinos Santa Inês: Estado de arte e perspectivas. In: SIMPÓSIO INTERNACIONAL SOBRE CAPRINOS E OVINOS DE CORTE, 2003, João Pessoa. Anais... SINCORTE, 2003. p.501-522.

STATISTICAL ANALYSIS SYSTEM - SAS. SAS/STAT: user's guide, Version 6, 4.ed., v.2. Cary: SAS Institute, 2001.

SUGUISAWA, L.; VARGAS JUNIOR, F.M.; MARQUES, A.C.W. et al. Características de carcaça e qualidade de carne por ultrassonografia em cordeiros confinados. In: CONGRESSO INTERNACIONAL DE ZOOTECNIA, 10., 2008, João Pessoa. Anais... João Pessoa: ZOOTEC, 2008. (CD-ROM).

TAROUCO, J.U.; LOBATO, J.F.P.; TAROUCO, A.K. et al. Relação entre medidas ultra-sônicas e espessura de gordura subcutânea ou área de olho-de-lombo na carcaça em bovinos de corte. Revista Brasileira de Zootecnia, v.34, n.6, p.2074-2084, 2005. 